\title{
Percepção das gestantes acerca da participação e envolvimento do parceiro/pai na gestação
}

\author{
Perception of pregnant women about the participation and involvement of the partner / \\ father in pregnancy \\ Percepción de la mujer embarazada sobre la participación e implicación de la pareja / \\ padre en el embarazo
}

Eloisia Maria Borel', Wilma Lucia Pereira Rangel Braga de Rezende ${ }^{2}$, Manuela Gomes Campos Borel $^{3}$, Thayenne Barrozo Mota Monteiro ${ }^{4}$, Alanna Fernandes Paraíso ${ }^{4}$, Érika Andrade e Silva ${ }^{4}$, Zuleyce Maria Lessa Pacheco ${ }^{4}$, Nathália Alvarenga Martins ${ }^{4}$, Delmar Teixeira Gomes ${ }^{4 *}$.

\section{RESUMO}

Objetivo: Avaliar as condições de participação do homem na gravidez de sua companheira na percepção das gestantes atendidas nos serviços de Atenção Primária à Saúde. Métodos: Estudo qualitativo do tipo descritivo exploratório, com 24 gestantes no segundo ou terceiro trimestre de gestação, acompanhadas no pré-natal. Para a análise dos dados utilizou-se a análise de conteúdo na perspectiva de Bardin, emergindo três categorias: a participação paterna na gestação; percepções das gestantes sobre o envolvimento paterno e, dificuldades para a participação do homem/pai na gestação. Resultados: Evidencia-se, a presença e envolvimento do pai que compreende diversos aspectos, principalmente o vínculo emocional e a afetividade. Ainda, uma posição paterna mais envolvida em atividades antes vistas como apenas maternais, porém ainda pouco presente nas rotinas da atenção à saúde. Conclusão: $O$ acolhimento e inclusão do pai nas ações de saúde relacionadas à gestação e ao pré-natal devem ser incentivado pelos profissionais de saúde, juntamente aos avanços na implementação dos programas de saúde relacionados ao ciclo grávido puerperal.

Palavras-chave: Gravidez, Paternidade, Políticas de saúde, Cuidado pré-natal.

\begin{abstract}
Objective: To evaluate the conditions of participation of men in the pregnancy of their partner, according to the understanding of pregnant women in Primary Health Care in a municipality in Minas Gerais. Methods: Qualitative descriptive exploratory study, with 24 pregnant women in the second or third trimester of pregnancy, followed up during prenatal care. For data analysis, content analysis was used from the perspective of Bardin, with three categories emerging: paternal participation in pregnancy; perceptions of pregnant women about paternal involvement and difficulties for the participation of man / father in pregnancy. Results: It is evident, the presence and involvement of the father that comprises several aspects, mainly the emotional bond and affectivity. Still, a fatherly position more involved in activities previously seen as only maternal, but still little present in health care routines. Conclusion: The reception and inclusion of the father in health actions related to pregnancy and prenatal care should be encouraged by health professionals, along with advances in the implementation of health programs related to the pregnant puerperal cycle.
\end{abstract}

Keywords: Pregnancy, Paternity, Health policy, Prenatal care.

\footnotetext{
${ }^{1}$ Hospital Sofia Feldman, Belo Horizonte - MG.

${ }^{2}$ Faculdade do Sudeste Mineiro de Juiz de Fora (FACSUM), Juiz de Fora - MG.

${ }^{3}$ Escola de Enfermagem Anna Nery, Universidade Federal do Rio de Janeiro (EEAN/UFRJ), Rio de Janeiro - RJ.

${ }^{4}$ Universidade Federal de Juiz de Fora (UFJF), Juiz de Fora - MG. *E-mail: gomesddt@gmail.com
} 


\section{RESUMEN}

Objetivo: Evaluar las condiciones de participación de los hombres en el embarazo de su pareja, de acuerdo con el entendimiento de las mujeres embarazadas en Atención Primaria de Salud en un municipio de Minas Gerais. Métodos: Estudio exploratorio descriptivo cualitativo, con 24 mujeres embarazadas en el segundo o tercer trimestre del embarazo, seguidas durante la atención prenatal. Para el análisis de datos, el análisis de contenido se utilizó en la perspectiva de Bardin, con tres categorías emergentes: participación paterna en el embarazo; percepciones de las mujeres embarazadas sobre la participación paterna y dificultades para la participación del hombre / padre en el embarazo. Resultados: Es evidente, la presencia y participación del padre que comprende varios aspectos, principalmente el vínculo emocional y la afectividad. Aún así, una posición paternal más involucrada en actividades que anteriormente se consideraban solo maternales, pero todavía poco presentes en las rutinas de atención médica. Conclusión: La recepción e inclusión del padre en las acciones de salud relacionadas con el embarazo y la atención prenatal debe ser impulsada por los profesionales de la salud, junto con avances en la implementación de programas de salud relacionados con el ciclo gestacional puerperal.

Palabras clave: Embarazo, Paternidad, Política de salud, Atención prenatal.

\section{INTRODUÇÃO}

A paternidade representa uma transformação em que o homem na sua função parental, procura adquirir competências e habilidades para serem suficientes aos seus filhos, sendo desenvolvidas e aperfeiçoadas durante a gestação. É uma responsabilidade que cria expectativas e transcende a relação biológica em que muitos se imaginam desempenhando o papel de pai e se preparam para o exercício dos cuidados exigidos, que vão se tornando mais complexos à medida do crescimento e desenvolvimento da criança (RIBEIRO JP, et al., 2015; PETITO ADC, et al., 2015).

A gestação e o cuidado dos filhos são percebidos socialmente como habilidades naturais femininas, pautadas no "instinto materno", pois se atribui às mulheres sentimento de afeto, já que a elas foram ensinadas, desde a infância, a experiência da maternidade (GABRIEL MR e DIAS ACG, 2011; BERNARDI D, 2017). Assim, a gestação acaba sendo reconhecida como um "momento da mulher" dificultando a aproximação do pai no processo gestacional (FABBRO MRG e LIMA MP, 2017).

Porém, o exercício paterno e o papel do pai na família sofreram mudanças ao longo da história, transformações econômicas, sociais e culturais ocorridas nos últimos séculos ajudaram a construir uma nova concepção de paternidade, em que o afeto e o cuidado passaram a ser valorizados. Contudo, na representação social ainda existe velhos discursos que influenciam os papéis maternos e paternos (OLIVEIRA AG e SILVA RR, 2011; BORSA JC e NUNES MLT, 2011; BERNARDI D, 2017).

Várias formas de atuação do pai durante a gestação podem ocorrer em diferentes aspectos, sejam emocionais ou materiais (ALIO AP, et al., 2013; SANTOS SC e KREUTZ CM, 2014). Nessa perspectiva, o pai que participa do processo, divide experiências, adquire práticas no cuidado e informações que auxiliam na formação de vínculos com os filhos, o que trará benefícios para a criança, além da relevância para o desenvolvimento da paternidade (PETITO ADC, et al., 2015).

Muitos homens têm motivações para participarem da assistência pré-natal e desejam dar suporte à esposa ou companheira durante a gestação, demonstrando satisfação ao participarem das consultas e acompanharem exames como a ultrassonografia (FIGUEIREDO MGAV e MARQUES AC, 2011; PETITO $A D C$, et al., 2015). No entanto, a figura paterna ainda tem se envolvido pouco no cuidado pré-natal e no processo gestacional, mesmo diante do interesse dos parceiros em participar das ações relacionadas à gestação (PESAMOSCA LG, et al., 2008).

A cooperação paterna ainda não é realidade dos serviços e é uma prática pouco aderida no Sistema Único de Saúde (SUS) porém, o motivo recai sobre um discurso de desinteresse do parceiro, o que nem sempre é verdade (CABRITA BAC, et al., 2012; COSTA SF e TAQUETTE SR, 2017). 
A escassez de material educativo com a participação paterna no processo gestatório induz a interpretação de ambientes exclusivamente femininos. Logo, os homens não se sentem inseridos, sendo a presença do pai indiferente e desvalorizada, até mesmo nos atendimentos, pois muitos comparecem apenas na função de acompanhantes, enquanto esperam do lado de fora da sala (COSTA SF e TAQUETTE SR, 2017).

Nesse contexto, o apoio das práticas institucionais, dos serviços e políticas de saúde, das normas e legislações são fatores determinantes do grau de envolvimento paterno e podem contribuir para inserir o homem no contexto gestacional (GARCÊS MMF, 2011; PETITO ADC, et al., 2015).

No Brasil, essa perspectiva de inclusão do homem na saúde da mulher e de sua participação no planejamento familiar é incentivado pelo Programa de Assistência Integral à Saúde da Mulher (PAISM) (1984) e pela Lei no. 9.263/96, que trata do planejamento familiar e garante a mulher, ao homem e ao casal o atendimento integral à saúde, incluíndo o pré-natal (BRASIL, 1996).

Porém, somente em 2008, o Ministério da Saúde (MS) divulga a Política Nacional de Atenção Integral à Saúde do Homem (PNAISH), voltada exclusivamente à saúde masculina. Esta, fortalece à inclusão do homem na saúde reprodutiva ao considerar a paternidade um direito e não apenas algo de obrigação legal (CABRITA BAC, et al., 2012).

Da mesma forma, ao potencializar o acesso dos homens aos serviços de saúde, o pré-natal do parceiro vem como uma experiência e impulsiona sua implementação. A caderneta da gestante, elaborada em 2016 pelo MS em conjunto com as Secretarias de Saúde Estaduais, Municipais e do Distrito Federal, inclui um espaço para informações específicas e registro dos dados do parceiro, como exames realizados e vacinas (BRASIL, 2016; SANTOS EM e FERREIRA VB, 2017).

Na percepção de incentivar o homem no processo gravídico-puerperal, em 2005, foi criada a Lei nำ11.108 que assegura a presença do acompanhante, a escolha da mulher durante o trabalho de parto, parto e pósparto imediato (BRASIL, 2005). Em 2016, foi publicada a Lei $n^{0} 13257 / 2016$, que dá ao pai o direito de acompanhar a sua esposa nas consultas de pré-natal (BRASIL, 2016; COSTA SF e TAQUETTE SR, 2017; HENZ GS, et al., 2017).

O profissionais da equipe de saúde da família, tem dentre suas atribuições, a realização da assistência à mulher inclusive no pré-natal ou seu acompanhamento a depender da categoria profissional, portanto, estes profissionais devem desenvolver e aprofundar ações que promovam a inclusão e maior participação do homem no período gravídico.

Considerando a integração do pai no processo gestacional, o estudo objetivou avaliar as condições de participação do homem na gravidez de sua companheira na percepção das gestantes atendidas nos serviços de Atenção Primária à Saúde. Para estes autores é fundamental considerar a percepção das gestantes quanto à participação do companheiro na gestação, uma vez que uma postura mais permissiva das próprias gestantes pode facilitar a entrada do pai no processo.

\section{MÉTODOS}

Trata-se de um estudo de abordagem qualitativa, do tipo descritivo exploratório. $\mathrm{O}$ cenário inclui 4 Unidades Básicas de Saúde (UBS), que dispõem de Estratégia de Saúde da Família (ESF), do município de Juiz de Fora em Minas Gerais.

Inicialmente, foi realizado um contato com as supervisoras das unidades, as quais sugeriram estratégias diferentes de aproximação e convite às gestantes. Em duas, foi realizada mediação pelos Agentes Comunitários de Saúde (ACS) que também acompanharam a pesquisadora em visitas domiciliares.

$\mathrm{Na}$ terceira unidade, as enfermeiras de cada área disponibilizaram o contato telefônico e endereço das gestantes, sendo que as ligações e busca em domicílio ficaram a cargo da pesquisadora. Já na quarta, as gestantes foram abordadas nas agendas de pré-natal durante a rotina das unidades. A coleta de dados ocorreu em março e abril de 2018. 
Incluíram-se no estudo, 24 gestantes, com idade igual ou maior que 18 anos, que estavam no segundo ou terceiro trimestre de gestação, usuárias do serviço de Atenção Primária à Saúde de Juiz de Fora e que expressaram desejo de participar voluntariamente da pesquisa, por meio da assinatura do Termo de Consentimento Livre e Esclarecido (TCLE). Excluíram-se gestantes que apresentaram alguma doença ou agravo à saúde que dificultaria a comunicação.

Para a coleta de dados, realizou-se uma entrevista semi-estruturada orientada por um instrumento composto por duas partes, a primeira contempla as características sociodemográficas das participantes, enquanto a segunda, questões relativas às percepções das gestantes sobre a participação paterna durante a gravidez.

As entrevistas duraram em média 15 minutos, sendo as mesmas gravadas e, após a saturação dos dados, o material foi transcrito de forma fidedigna e submetido à análise temática de conteúdo de Bardin. Este, se organiza através de fases em torno de três polos cronológicos: pré-análise; exploração do material; e tratamento dos resultados, inferência e interpretação (BARDIN, 2011).

Seguindo os pressupostos da primeira etapa, procedeu-se a organização do material pela transcrição das falas na íntegra. As gravações foram conservadas e o material foi preparado para análise, seguindo a leitura exaustiva do transcrito e edição do texto.

$\mathrm{Na}$ fase de exploração do material para codificação e agregação dos dados, buscou-se temas centrais transmitidos nas entrevistas permitindo um agrupamento temático de onde surgiram três categorias: a participação paterna na gestação; percepções das gestantes sobre o envolvimento paterno e, dificuldades para a participação do homem/pai na gestação.

Já na terceira etapa, foi realizado o tratamento dos resultados, a inferência e a interpretação dos resultados brutos que foram tratados de maneira a serem válidos e significativos. Nesse sentido, a partir das categorias levantadas, seguiu-se a análise e interpretação de acordo com o referencial teórico, sendo explorados os resultados obtidos e comparados com a perspectiva de outros autores.

Esta pesquisa foi desenvolvida assegurando os preceitos éticos que regem as investigações envolvendo seres humanos (BRASIL, 2012), uma vez que os dados foram coletados após aprovação do Comitê de Ética em Pesquisa da Universidade Federal de Juiz de Fora, sob parecer no2.518.314/2018. O sigilo das participantes foi garantido por codificação do seu nome pela letra E seguida por número, exemplo E1, E2, ..., E24.

\section{RESULTADOS}

Participaram da pesquisa 24 gestantes com faixa etária entre 18 e 38 anos, destas, 13 se declaram pardas, 6 brancas, 4 negras e 1 amarela. Em relação à escolaridade apenas 2 possuiam formação superior, 10 o segundo grau completo, 8 o primeiro grau completo e 4 o primeiro grau incompleto. A respeito do trabalho, apenas 13 trabalhavam. As principais ocupações foram: embaladora de meias, secretária, atendente e coordenadora de telemarketing, assistente social, operadora de máquina, auxiliar de almoxarifado, cozinheira/auxiliar de cozinha, caixa e balconista. Em relação ao estado civil, 7 são casadas, 6 afirmaram residir com o companheiro, já as outras 11 gestante são solteiras e não possuem companheiro.

Quanto à paridade, 11 são primigestas e 13 multíparas. A idade gestacional, no momento da coleta de dados, compreendia entre 19 e 38 semanas de gestação, com uma média de 29,67 semanas. Em relação ao planejamento da gravidez pelo casal, 15 gravidezes não foram planejadas, enquanto 9 responderam afirmativamente ao questionamento. Uma das participantes ficou em dúvida quanto à resposta, pois o planejamento era vindo mais da parte paterna.

\section{A participação paterna na gravidez}

O comparecimento nos exames de ultrassom foi uma forma recorrente durante as falas das entrevistadas para evidenciar a participação do pai. 


\section{[...] mas ultrassom e tudo ele vai, ele arruma um jeitinho e vai (E1) \\ [...] agora nessa daí que eu vou fazer a ultrassom ele quer ir comigo pra ver, porque é diferente né essa vai mostrar tudo, aí ele quer ir, ele vai ver se consegue ir [...] (E2)}

O companheiro se interessa pelos acontecimentos na assistência pré-natal demostrando curiosidade e preocupação.

[..] ele sempre me pergunta como foi e aí o que a médica falou [...] (E2)

[...] ele é muito participativo, ele pergunta tudo, tudo ele pergunta. Ele não participa das consultas, mas tudo ele pergunta [...] Ele é muito preocupado (E3)

O apoio do companheiro foi destacado como a principal forma de participação durante o período gestacional.

Ah na parte emocional, porque eu tenho depressão e eu tinha parado meu tratamento de depressão por causa da gravidez, então eu tenho que tomar um remédio mais leve, então ele tem me ajudado muito na parte psicológica minha sabe? [...] então ele é muito carinhoso comigo [...] tem sido um companheiro muito bom pra mim, e eu também sou muito tranquila né, acho que vai ajudando também um ao outro, companheirismo, respeito [...] (E4)

É notório a participação ativa por parte do companheiro para poupar a mulher em esforço físico auxiliandoas nas tarefas diárias. $O$ homem adota condutas de tolerância e benevolência diante da condição gravídica da companheira.

[...] tudo o que eu peço, é dentro de casa pra me ajudar, tudo ele me ajuda, tudo. [...] às vezes eu preciso de arrumar uma casa aí fica assim, 'fica tranquila deixa que eu arrumo', é fazer um almoço ele faz, é em tudo. [...] eu não preciso levantar nem pra pegar água, porque tudo ele leva pra mim sabe (E4)

A participação do companheiro demonstra uma posição paternal mais envolvida com atividades antes vistas como apenas maternais.

Ah a gente vai na cidade, compra as roupinhas, a gente tá escolhendo os nomes (E5)

[...] a gente senta pra planejar o que vai comprar para o bebê [...] ele já foi comprar ele trouxe pra mim uma roupinha, acho que é mais isso, de planejar a vinda do bebê. [...] igual a gente tá em reforma, a questão da reforma da casa, ele quer priorizar o quartinho $[\ldots](E 3)$

O auxílio econômico por parte do companheiro também foi citado durante as entrevistas como uma forma de participação paterna na gestação.

[...] se eu precisar de alguma coisa, algum remédio que precise comprar por conta de vitamina e eu pedir ele compra. Tanto pra mim quanto pra criança se precisar de algum acoisa é só falar pra ele que ele me ajuda (E6)

ele compra, remédio se eu tiver de tomar remédio ele vai, exame se eu tiver que fazer ele mesmo paga (E7)

\section{Percepção das gestantes sobre o envolvimento paterno}

As gestantes mencionaram sentimentos de satisfação e felicidade quanto a participação do companheiro na gestação, reconhecendo a assistência recebida por eles e apontaram agradecimento.

[...] é uma alegria e graças a Deus tá tudo bem, é um sentimento só de alegria, só de satisfação (E6)

Ah de agradecimento! (risos) ele faz o que pode pra ajudar [...]. (E8) 
Em alguns relatos observou-se que as mulheres entrevistadas se surpreenderam com a participação do companheiro na atual gestação superando as expectativas esperadas.

[...] ele tá participando entendeu, e eu não imaginava que seria assim. Eu imaginei que ele ia participar, mas não tanto (E9)

A figura do companheiro se apresenta como uma pessoa colaborativa a quem se recorre para dividir dúvidas, medos, ansiedades e angústias.

Ele é tudo, tá sendo um companheiro, eu não preciso nem de contar com minha mãe, coisa de gravidez eu nem falo com minha mãe, porque tudo que eu preciso, toda a dúvida que eu tenho é ele [...]. [...] agora a médica acabou de falar comigo ali que tô no final, que a qualquer momento pode nascer, eu tava muito nervosa, agora tô bem tranquila porque eu sei que eu tenho ele [...] (E4)

\section{Dificuldades para a participação do companheiro/pai na gestação}

Dentre as dificuldades à participação do companheiro na gestação está relacionado aos horários das consultas como pouco favoráveis para a inclusão do pai nas consultas de pré-natal.

\section{[...] igual assim consulta essas coisas não dá por causa do serviço né [...] (E10) \\ [...] só nessas partes de consultas de pré-natal e essas coisas que às vezes não dá pra ele poder ir por causa do horário de trabalho dele que é meio complicado (E11)}

Outra dificuldade apontada pelas entrevistadas para o envolvimento paterno foi a demora do companheiro em reconhecer a paternidade.

Ah homem..., eles não mostram muito sentimento por isso não né, só depois que nasce $[\ldots](E 12)$

A atual situação do relacionamento do casal, situações de brigas até mesmo filhos de outros relacionamentos podem contribuir para o afastamento do pai.

[...] a gente terminou agora, aí agora ele fica falando que quer participar que a filha vai crescer longe dele, que não sei o que lá, mas ele não pensou nisso né (E13)

A gente parou de conversar. Então, na verdade, a gente teve uma discussão, uma briga [...] aí eu não converso com ele hoje mais [...] a gente já tava meio brigando aí a gente parou de conversar [...] nem ele procura e nem eu procuro [...] Ele poderia ter desenvolvido a vontade de participar, mas não quis então eu também não fui atrás. Aí eu preferi assim (E14)

Outro fator dificultador para a participacao mais presente do pai durante a gestação envolve a distância força da devido a questões adversas como situação prisional também.

[...] acho que ele não participa mais porque não dá. Porque meu marido é preso né, então não dá [...] aí interfere né, porque ele não tem o que fazer, mas na medida do possivel ele tá bem presente (E15)

\section{DISCUSSÃO}

Observa-se um esforço por parte do companheiro e desejo em comparecer aos exames, principalmente nos exames de ultrassonografia, também conhecido como ultrassom. O exame de ultrassom é visto como estratégia para contribuir na construção da imagem mental do pais sobre o bebê, permite ao homem visualizar os contornos e escutar os batimentos do coração (FIGUEIREDO MGAV e MARQUES AC, 2011; CALDEIRA LA, et al., 2017). Pelas entrevistas, percebeu-se o envolvimento paterno evidenciado na participação dos homens nos exames de ultrassom, quando comparado às consultas de pré-natal.

Sabe-se porém, que o envolvimento paterno compreende diversos aspectos, não se restringindo apenas em acompanhamento de consultas ou exames. Também inclui vínculo emocional com a mulher e/ou o filho, respeito, afetividade e participação ao transmitir tranquilidade, atenção, segurança e amor (ZAMPIERI MFM, et al., 2012). 
No período da gestação a mulher pode desenvolver sentimentos de ansiedade e abandono social necessitando de maior proteção e amparo (SANTOS SC e KREUTZ CM, 2014; CALDEIRA LA, et al., 2017). Ao considerar que o "pai ideal", envolvido com a gravidez, é aquele que se mostra presente, acessível e disponível (ALIO AP, et al., 2013). Compreende-se, como um pai ativo, aquele que se preocupa com a gravidez, faz perguntas à gestante e ao profissional de saúde, se interessa em aprender sobre o processo, fornece apoio físico e emocional (BRASIL, 2016).

Além disso, ajudar a cuidar da alimentação, exercitar-se em conjunto com a gestante e prezar pela manutenção de hábitos saudáveis, bem como privar a mulher fazer de esforço físico que coloque a gestação em risco, são exemplos de maneiras que os homens encontram para registrar sua participação (SANTOS SC e KREUTZ CM, 2014).

O auxílio econômico por parte do companheiro também é citado como uma forma de participação paterna, não em uma visão tradicional de provedor financeiro, mas como preocupação com a saúde da companheira e do filho. Tal participação pode influenciar o bem-estar da mulher seja pela sua presença, aceitação e prazer de estar junto (FREITAS WMF, et al., 2007; SANTOS SC e KREUTZ CM, 2014).

A participação do companheiro durante o pré-natal e gestação transmite sentimentos de segurança e afeto à mulher bem como incentivo na continuidade do acompanhamento (MARTELLO NV, et al., 2017). As participantes demonstram maior tranquilidade e segurança ao conseguirem compartilhar as informações referentes ao pré-natal e a rotina das consultas. E conforme evidenciado nos relatos das gestantes entrevistadas, a conexão emocional, romântica ou a falta dela pode influenciar fortemente o nível de envolvimento do pai, bem como o bem-estar mental da mãe durante e após a gravidez.

Quando o pai está envolvido, os comportamentos de saúde negativos maternos diminuem, o que resulta em benefícios para a gestante e para o bebê (ALIO AP, et al., 2013). Inteirado sobre os conhecimentos acerca dos cuidados relacionados à gravidez, o pai também pode contribuir para a prática do aleitamento materno e serem mais atuantes no trabalho de parto e parto (ALIO AP, et al., 2013; FERREIRA IS, et al., 2016; CALDEIRA LA, et al., 2017).

Muitos pais desconhecem o seu direito em acompanhar a gestante na consulta pré-natal (FIGUEIREDO MGAV e MARQUES AC, 2011). Outros, referem que o principal motivo para a ausência do companheiro/pai no momento do pré-natal é a incompatibilidade de horários entre seu trabalho e o horário dos atendimentos nas Unidades Básicas de Saúde, o que provoca receio de pedir liberação no trabalho e sofrerem perseguições (CALDEIRA LA, et al., 2017; HENZ GS, et al., 2017; COSTA SF e TAQUETTE SR, 2017; GOMES D, 2017).

Ademais, alguns homens só desenvolvem o sentimento de paternidade com a evolução da gravidez, talvez por não contar com a realidade das mudanças corporais e do desenvolvimento da criança no seu próprio corpo, o que leva a figura paterna ter que vincular em seu imaginário a materialização do bebê para o desenvolvimento de um vínculo (CALDEIRA LA, et al., 2017; GOMES D, 2017).

Da mesma forma, a atual situação do relacionamento do casal, situações de brigas até mesmo filhos de outros relacionamentos podem contribuir para o afastamento do pai. A conexão emocional ou romântica ou a falta dela pode influenciar fortemente o nível de envolvimento do pai, bem como o bem-estar mental da mãe durante e após a gravidez. A difícil relação com a mãe das crianças contribui para que o pai não tenha uma relação mais estreita com os filhos, refletindo na quebra do vínculo, assim como em situações de separação conjugal (ALIO AP, et al., 2013; CÚNICO SD e ARPINI DM, 2013).

\section{CONCLUSÃO}

Apesar de fazer necessário uma maior de inclusão do homem/pai durante a gestação e vida do bebê, neste estudo, foi possível avaliar as condições de participação do homem na gravidez de sua companheira a partir da percepção das gestantes. Os homens têm se mostrado mais envolvidos e interessados, porém a participação estrapola o acompanhamento em consultas e exames para o vínculo emocional, o apoio, atenção, carinho e afeto. Este estudo contribui para a enfermagem ao evidenciar a importância das pesquisas relacionadas ao protagonismo do pai no processo gravídico-puerperal e sua participação na área relativa à saúde sexual e reprodutiva, bem como promover novas estratégias e ações de acolhimento do homem nos serviços de saúde. 


\section{REFERÊNCIAS}

1. ALIO AP, et al. A community perspective on the role of fathers during pregnancy: a qualitative study. BMC Pregnancy Childbirth, 2013; 13: 60.

2. BARDIN, L. Análise de conteúdo. São Paulo: Almedina, 2011; 280 p.

3. BERNARDI D. Paternidade e cuidado: "novos conceitos", velhos discursos. Psicologia Rev., 2017; 26(1): 59-80.

4. BORSA JC, NUNES MLT. Aspectos psicossociais da parentalidade: o papel de homens e mulheres na família nuclear. Psicologia Argumento, 2011; 29(64): 31-39.

5. BRASIL, 1996. In: LEI № 9.263, DE 12 DE JANEIRO DE 1996, regula o § $7^{\circ}$ do art. 226, da Constituição Federal, que trata do planejamento familiar, estabelece penalidades e dá outras providências. Brasil: Presidência da Repúbica. Disponível em: www.planalto.gov.br/ccivil_03/leis/l9263.htm. Acesso em: 10 de dez. 2020.

6. BRASIL, 2005. In: LEI № 11.108, DE 7 DE ABRIL DE 2005. Altera a Lei № 8.080 , de 19 de setembro de 1990, para garantir às parturientes o direito à presença de acompanhante durante o trabalho de parto, parto e pós-parto imediato, no âmbito do Sistema Único de Saúde - SUS. Presidência da República. Disponível em: www.planalto.gov.br/ccivil_03/_ato20042006/2005/lei//11108.htm. Acesso em: 10 de dez. 2020.

7. BRASIL. Ministério da Saúde. CNS. Conselho Nacional de Saúde. RESOLUÇÃO № 466, DE 12 DE DEZEMBRO DE 2012. Aprova diretrizes e normas regulamentadoras de pesquisas envolvendo seres humanos. Diário Oficial da União, Brasilia 12 de dezembro de 2012. Disponivel em: www.conselho.saude.gov.br/resolucoes/2012/Reso466.pdf. Acesso em: 10 dez. 2020.

8. BRASIL, 2016. In: LEI № 13.257, DE 8 DE MARÇO DE 2016, dispõe sobre as políticas públicas para a primeira infância e altera a Lei no 8.069, de 13 de julho de 1990 (Estatuto da Criança e do Adolescente), o Decreto-Lei no 3.689, de 3 de outubro de 1941 (Código de Processo Penal), a Consolidação das Leis do Trabalho (CLT), aprovada pelo Decreto-Lei no 5.452, de 1ㅇ de maio de 1943, a Lei no 11.770, de 9 de setembro de 2008, e a Lei no 12.662, de 5 de junho de 2012. Brasil: Presidência da República. Disponível em: www.planalto.gov.br/ccivil_03/_ato2015-2018/2016/lei/13257.htm. Acesso em: 10 de dez. 2020.

9. BRASIL. Ministério da Saúde. Guia do Pré-natal do parceiro para profissionais de saúde. Rio de Janeiro, $1^{a}$ edição. 2016.

10. BRASIL. Ministério da Saúde. Caderneta da Gestante. Brasília, Distrito Federal, 3ª edição. 2016.

11. CABRITA BAC, et al. A ausência do companheiro nas consultas de pré-natal: desafios e conquistas. Revista de Pesquisa Cuidado é Fundamental Online, 2012; 4(3):2645-2654.

12. CALDEIRA LA, et al. A visão das gestantes acerca da participação do homem no processo gestacional. Revista de Enfermagem do Centro-Oeste Mineiro, 2017; 7: e1417.

13. COSTA SF, TAQUETTE SR. Atenção à gestante adolescente na rede SUS - O acolhimento do parceiro no pré-natal. Rev. enferm. UFPE on line, 2017; 11(supl.5):2067-74.

14. CÚNICO SD, ARPINI DM. O afastamento paterno após o fim do relacionamento amoroso: um estudo qualitativo. Interação em Psicologia, 2013; 17(1):99-108.

15. FABBRO MRG, LIMA MP. A experiência paterna de pais de "primeira viagem" no cuidado do bebê nos primeiros três meses de vida. Investigação Qualitativa em Saúde, 2017; 2: 166-75.

16. FERREIRA IS, et al. Percepções de gestantes acerca da atuação dos parceiros nas consultas de pré-natal. Rev. Rene, 2016; 17(3): 318-23.

17. FIGUEIREDO MGAV, MARQUES AC. Pré-natal: experiências vivênciadas pelo pai. Cogitare Enfermagem, 2011; 16(4): 70813.

18. FREITAS WMF, et al. Sentir-se pai: a vivência masculina sob o olhar de gênero. Cadernos de Saúde Pública, 2007; 23(1): 137-145.

19. GABRIEL MR, DIAS ACG. Percepções sobre a paternidade: descrevendo a si mesmo e o próprio pai como pai. Estudos de Psicologia, 2011; 16(3): 253-261.

20. GARCÊS, MMF. Vivências da figura paterna no trabalho de parto e nascimento no processo de transição para a parentalidade. Dissertação (Mestrado em Enfermagem de Saúde Materna e Obstetrícia). Escola Superior de Enfermagem do Porto, Porto, 2011; 130 p.

21. GOMES, D. Pré-Natal do Homem: Expectativas, Dificuldades e Vulnerabilidades. Tese (Doutorado em Ciências da Saúde) - Faculdade de Enfermagem. Universidade Estadual de Campinas, Campinas, 2017; 135 p.

22. HENZ GS, et al. A inclusão paterna durante o pré-natal. Revista de Enfermagem e Atenção à Saúde, 2017; 6(1): 52-66.

23. MARTELLO NV, et al. Percepções de gestantes acerca da participação do companheiro na gestação. Saúde (Santa Maria), 2017; 43(2):21-26.

24. OLIVEIRA AG, SILVA RR. Pai contemporâneo: diálogos entre pesquisadores brasileiros no período de 1998 a 2008. Psicologia argumento, 2011; 29(66): 353-360.

25. PESAMOSCA LG, et al. Percepção de gestantes acerca da importância do envolvimento paterno nas consultas pré-natal: um olhar de gênero. Revista Mineira de Enfermagem, 2008; 12(1):182-188.

26. PETITO ADC, et al. A importância da participação do pai no ciclo gravídico puerperal: uma revisão bibliográfica. Revista Eletrônica da Faculdade de Ceres, 2015; 4(1):1.

27. RIBEIRO JP, et al. Participação do pai na gestação, parto e puerpério: refletindo as interfaces da assistência de enfermagem. Revista Espaço para a Saúde, 2015; 16(3): 73-82.

28. SANTOS EM, FERREIRA VB. Pré-natal masculino: significados para homens que irão (re) experienciar a paternidade. Revista Funec científica-multidisciplinar, 2017; 5(7): 62-78.

29. SANTOS SC, KREUTZ CM. O envolvimento do pai na gestação do primeiro filho. Pensando famílias, 2014; 18(2): 62-76.

30. ZAMPIERI MFM, et al. O significado de ser pai na ótica de casais grávidos: limitações e facilidades. Revista Eletrônica de Enfermagem, 2012; 14(3): 483-93. 